\title{
Analysis of Ventilation Rate in Cross Ventilated Rooms by Varying Aperture Shape of Windows using CFD
}

\author{
V. Sivakumar ${ }^{1 \dagger}$, K. Visagavel ${ }^{2}$ and A. Selvakumar ${ }^{2}$ \\ ${ }^{1}$ Department of Mechanical Engineering, M.A.M College of Engineering, Trichy. \\ ${ }^{2}$ Department of Mechanical Engineering, Knowledge institute of Technology, Salem. \\ †Corresponding Author Email: sivakumarpalapatti@gmail.com
}

(Received February16, 2017; accepted July 30, 2017)

\begin{abstract}
On this era of increasing energy demand, natural ventilation appears to be the proper solution as it provides the necessary ventilation required for the room by means of the natural forces, such as wind. It ensures salubrity and pleasant indoor climate through least possible energy consumption at least possible cost. Our project aims to identify the air velocities and air change per hour in a cross ventilated room through numerical predictions. The standards for natural ventilation are taken into account along with the heat transfer concepts and the analysis is carried out on different shapes of inlets and outlets at different heights. The models were analyzed using CFD software by using SIMPLE and SIMPLEC algorithm to solve the equations and the results are compared.
\end{abstract}

Keywords: Ventilation; Aperture shaped window; Computational fluid dynamics; Less energy consumption.

\section{INTRODUCTION}

In agreement with Domkundar (2015) and Jaina (2012) natural ventilation is defined as using passive strategies to supply outdoor air to a building's interior for ventilation and cooling. With proper design, appropriate to the building location and use, natural ventilation can replace all or part of a mechanical system. The need to reduce our consumption of energy and to give users more control over their immediate environments, are good reasons for people now to understand the role of natural ventilation in buildings and to become familiar with the basic principles involved. It serves the purpose of reducing not only the strain from your wallet but also on the environment. On this era of increasing energy demand, natural ventilation appears to be the proper solution as it provides the necessary ventilation required for the room by means of the natural forces, such as wind without the use of any depleting resources. It also ensures healthy and comfortable indoor climate through minimal energy consumption at minimal cost. Buildings can be ventilated mainly by two methods: Single-sided ventilation and Cross-sided ventilation. Both these involves the process of air flowing into the room, circulating and then exiting through the apertures which happen due to pressure differences through buoyancy and wind forces. The physical processes taking place due to this type of ventilation can be computed using analytical and numerical methods.

Allocca (2003) have studied the effects of ventilation in a single-sided room due to buoyancy, wind and their combination using analytical and empirical methods and found. From this study, it has been found that the stack and wind effects can either reinforce or may even oppose each other. There is no guiding rule for predicting the counteraction of wind and stack effect. In the investigation of Karagkouni (2013), two facades consisting of elastically deformable vertical louvers, were implemented to enable experimentation and a structure to improve the ventilation performance in a building was identified. Sinha (2002) have analyzed the distribution of air in a room with and without buoyancy effects by numerical means. Srinivasan (2007 and 2009) have studied the single-sided ventilated room applied CFD analysis for both wind-driven and buoyancy cases by using rectangular and convergent-divergent nozzle type openings. It showed that the nozzle type opening increases effective depth of ventilation in terms of airflow patterns and had moderate effect on $\mathrm{ACH}$. In a specific case, the atmospheric domain 
around the room has been taken into consideration and the analysis was carried. Analogous to Stavrakakis (2012) and prior successful designs by Engineering toolbox data, it was found that the increase in atmospheric velocity created recirculation zones in the room and the velocity in the room increased at various locations and it was suggested that the inside and outside locations has to be carefully placed in order to get better comfort. Also, a comparison between cross and single ventilated rooms by varying the size of an aperture brought the result that single-sided leeward ventilated room has the least effect and cross-ventilated rooms are most effective.

As cross-ventilation was found effective from the literature review and focusing in detail about cross ventilation would be more beneficial. Hence, this study uses computational fluid dynamics to identify the physical processes involved in a cross-sided ventilation room. This was done by taking three different openings- square shaped, convergentdivergent nozzle shaped and circular shaped opening. CFD analysis was used to solve the problem as the parameters can be varied effortlessly and the results can be obtained rapidly.

\section{Problem InVESTigation}

The ventilation aspects in a cross ventilation room are investigated. Fig. 1 shows the CFD domain2-Dimensions. $10 \times 10 \times 10 \mathrm{ft}$ room of height $\mathrm{H}=10 \mathrm{ft}$ and width $\mathrm{L}=10 \mathrm{ft}$ is considered for investigation. The room has an opening at height (h1) for inlet and another opening at height (h2) for outlet from the floor and is located on the vertical (building) walls. As it is crosssided naturally ventilated room, the air flow is through the inlet opening on the left side, passes through the room and flows out through the right opening using buoyancy effect. For this room, the opening shape is varied and the analysis is done. Also, analysis is made to compare the air change rate obtained from the analytical methods. The problem is investigated numerically using heat transfer concepts and analyzed by CFD software.

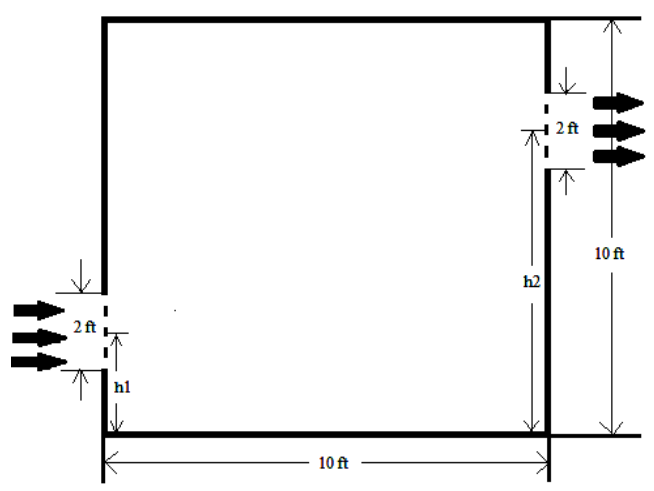

Fig. 1. Computational domains

\subsection{Analytical Methods Load Calculation}

We are taking a $10 \times 10 \times 10 \mathrm{ft}$ room as a sample room and the results are investigated.

The area of the ventilation opening used here is $2 \mathrm{x}$ $2 \mathrm{ft}$ opening.

A building or room has taken heat from various provenance. Inside occupants, computers, copiers, machinery, and lighting all produce heat. Warm air from outside comes in through open doors and windows, or as 'out pour' though the structure. However the solar radiation from the sun is biggest source of heat, beating down on the roof and walls, and penetrating through the open areas, heating inside of the room. So the major heating loads for a room are the envelope load, people load and fresh air load.

\section{Envelope Load:}

We know that, heat transfer $\mathrm{Q}=\mathrm{UA} \Delta \mathrm{T}$

The value of overall heat transfer coefficient $U$ can be obtained from ASHRAE 62.1 standards [1].

Considering the outdoor temperature of the room to be $30 \mathrm{C}$ and the desired indoor temperature to be 25 $\mathrm{C}$, the change in temperature appears to be $5 \mathrm{C}$.

Total envelope load, $\mathrm{Q}=(\mathrm{Q} 1+\mathrm{Q} 2+\mathrm{Q} 3+\mathrm{Q} 4+\mathrm{Q} 5$ + Q6) / 6

Where Q1 = Heat generated on wall with inlet

$$
\begin{aligned}
& \text { Q2 = Heat generated on wall with outlet } \\
& \text { Q3 = Heat generated on ceiling } \\
& \text { Q4 = Heat generated on the floor } \\
& \text { Q5 = Heat generated on other wall } \\
& \text { Q6 = Heat generated on other wall }
\end{aligned}
$$

Total envelope load, $\mathrm{Q}=1.146 \mathrm{~kW}$

\section{People Load:}

The interior of the room cooling load due to occupant endures both sensible and latent heat components. The rate at which the sensible and latent heat energy transfer turn up depends mainly on the group of the individuals and different movements of the occupants. Hence a part of the heat energy passed by the occupants in the form of radiation.

As per the standards, $20-50 \mathrm{ft} /$ person floor area is required for comfortable occupation and hence the no. of occupants for a $10 \mathrm{x} 10 \mathrm{ft}$ room is to be 5 .

The sensible heat and latent heat of the occupants can be obtained from ASHRAE 62.1 standards [1].

People load $=$ Total sensible load + Total latent load

$$
=0.55 \mathrm{~kW}
$$

\section{Fresh air rate:}

As per ASHRAE standard 62.1:6.2.2.1 [2], the design outdoor airflow (or) ventilation rate required in the occupiable space is given by

Ventilation rate, $\mathrm{V}=\mathrm{Rp} . \mathrm{Pz}+\mathrm{Ra} . \mathrm{Az}$ 


$$
\mathrm{V}=31 \mathrm{cfm}
$$

\section{Fresh Air Load:}

The fresh outdoor air enters the room through the openings. A load is added by the incoming fresh air which can be calculated using the sensible and latent heat of the air.

Fresh air load $=0.18 \mathrm{~kW}$

Total load in the room

$=$ Envelope load + People load + Fresh air load

$$
\begin{aligned}
& =1.146+0.55+0.18 \\
& =1.876 \mathrm{~kW}
\end{aligned}
$$

Amount of heat required to raise the temperature of the room:

We know that, heat transfer can also be expressed as $\mathrm{Q}=\mathrm{Cp} \cdot \mathrm{m} . \mathrm{dT}$

For a room of volume $1000 \mathrm{ft} 3$,

$\mathrm{dT}=40.6 \mathrm{~K}$

\section{Required air flow rate:}

In order to find the air change per hour it is essential to find the fresh air rate necessary for comfortable occupancy of the occupants.

So, the required air flow necessary for the desired ventilation level can be found using the equation,

Required air flow rate,

$$
L=\frac{\mathrm{Q}}{\mathrm{Cp}^{*} \rho^{*}(\mathrm{th}-\mathrm{tr})}
$$

Fresh air rate, $\mathrm{L}=79.45 \mathrm{ft}^{3} / \mathrm{min}$

\section{Ventilation Rate $\left(\mathrm{m}^{3} / \mathrm{s}\right)$ :}

As per CIBSE Guide B2, The rate at which air is exchanged is an important property for the purpose of ventilation design and heat loss calculations. This property is expressed in ventilation rate $\left(\mathrm{m}^{3} / \mathrm{s}\right)$.

Ventilation rate $\left(\mathrm{m}^{3} / \mathrm{h}\right)$

$=$ Air change rate $(/ \mathrm{h}) \times$ Room volume $\left(\mathrm{m}^{3}\right)$

Ach $=\frac{\text { fresh air rate } \times 100}{\text { volume of room }}$

Ach $=\frac{79.45 \times 60}{1000}$

Ach $=4.76^{h^{-1}}$

Ventilation rate $\left(\mathrm{m}^{3} / \mathrm{s}\right)=4.76 \times 1000 / 3600=1.32$

Therefore the air change rate for the required room has been calculated using the standards for ventilation and heat transfer concepts.

\section{Numerical methods}

The following assumption were considered, the governing equations are:

a) For Cartesian coordinate system was assigned and steady state heat transfer in two dimensions was considered.

b) The fluid property is considered as constant and isothermal.

c) The flow is not a laminar instead turbulent.

d) Final flow was feud to be Newtonian and in compressible.

Under these assumptions, the governing equations to be solved are as follows:

a) Continuity equation

$$
\frac{\partial \mathrm{u}}{\partial \mathrm{x}}+\frac{\partial \mathrm{v}}{\partial \mathrm{y}}=1
$$

Momentum equation in $\mathrm{x}$ and $\mathrm{y}$ direction

$$
\begin{aligned}
& u \frac{\partial v}{\partial x}+v \frac{\partial u}{\partial y}=\frac{1}{\rho} \frac{\partial \mathrm{P}}{\partial x}+\gamma\left(\frac{\partial^{2} v}{\partial x^{2}}+\frac{\partial^{2} u}{\partial y^{2}}\right) \\
& u \frac{\partial v}{\partial x}+v \frac{\partial u}{\partial y}=\frac{1}{\rho} \frac{\partial \mathrm{P}}{\partial y}+\gamma\left(\frac{\partial^{2} v}{\partial x^{2}}+\frac{\partial^{2} v}{\partial y^{2}}\right)
\end{aligned}
$$

Where $\rho$ is the density, $u$ the rate of change of displacement in $\mathrm{x}$-direction, $\mathrm{v}$ the rate of change of displacement in $y$-direction, and $\mathrm{p}$ is the pressure. For modeling the turbulent quantity, standard twoequation $\mathrm{k}-\varepsilon$ model is used. The above equations are solved numerically using the ANSYS CFD software.

The boundary conditions to solve the problem are:

a) The air flow is given in the inlet,

b) No slip boundary condition is applied on the floor

c) The building surface and the outlet has zero pressure boundary condition $(\mathrm{p}=0)$.

The object is created using the modeling software. Boundary layer type mesh is applied on the inside and outside of the buildings. The uniform or expanding grid spacing is applied over the remains regions. The whole region is treated as fluid (air) continuum. The basic conservation equations are solved numerically using the ANSYS CFD software. Time is constant in whole problem solver is activated.

Air as fluid is defined and the Boussinesq's model is selected. Gravity is activated. In boundary condition, value for the inlet-velocity magnitude has given. Iterated still the solution is calculated. The grid display, contour of properties, velocity vector and stream function are viewed from the 'Display' option.

\section{CASE 1:}

First, the room is set with a square shaped opening for both the inlet and outlet passages. The opening area is assumed to have an area of $2 \times 2 \mathrm{ft}$. The openings are kept at heights $\mathrm{h} 1=4 \mathrm{ft}$ and $\mathrm{h} 2=6 \mathrm{ft}$ from the floor and the results are taken. 
V. Sivakumar et al. / JAFM, Vol. 10, Special Issue, pp. 61-68, 2017.

Fig. 2 (a)
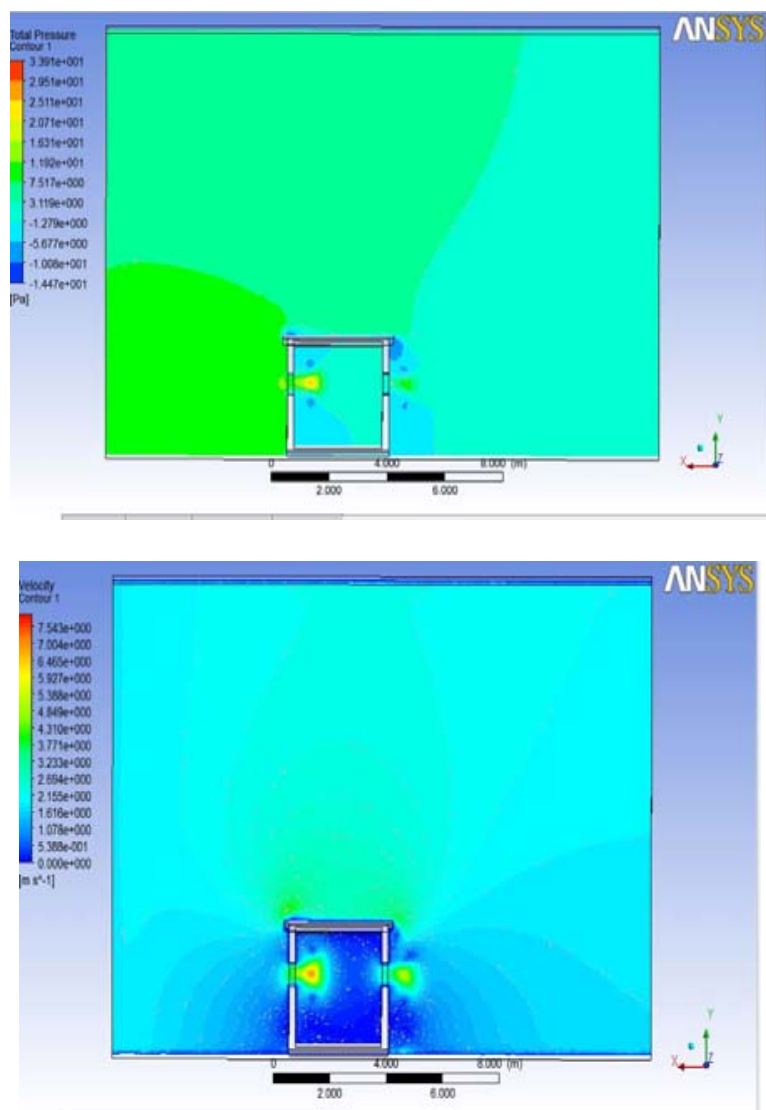

Fig. 2 (b)

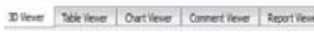

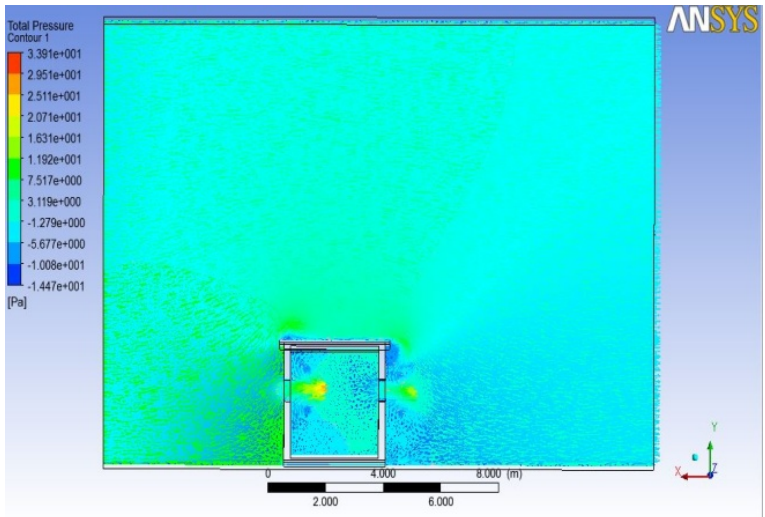

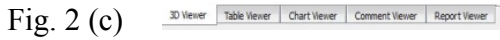

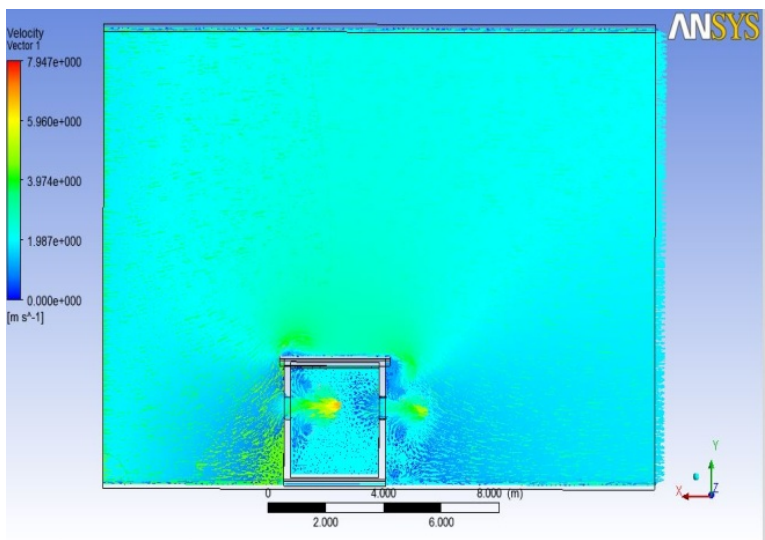

Fig. 2 (d)

Fig. 2. CFD results for the room with an inlet velocity of $0.11 \mathrm{~m} / \mathrm{s}$ (a) pressure (b) velocity (c) vector pressure (d) vector velocity. 
V. Sivakumar et al. / JAFM, Vol. 10, Special Issue, pp. 61-68, 2017.

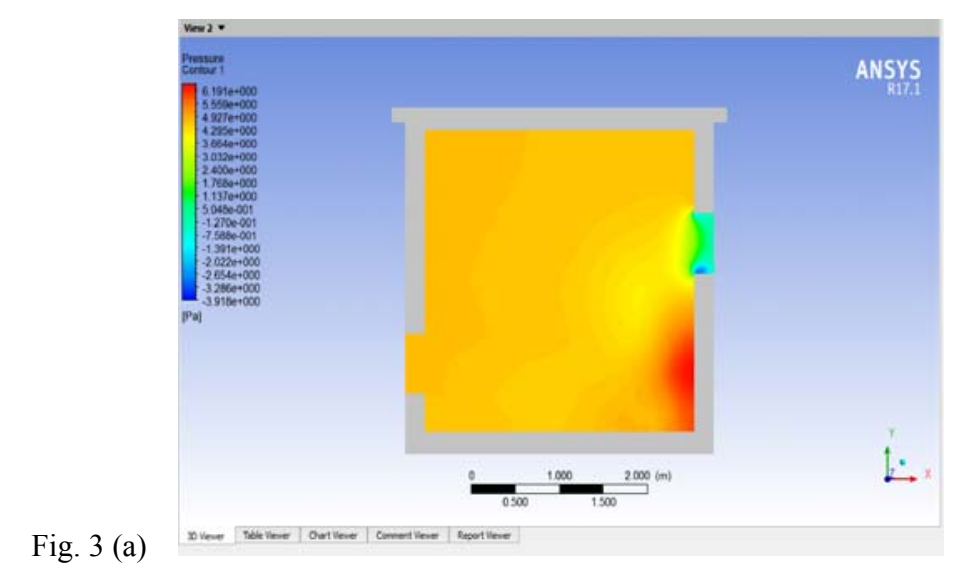

Fig. 3 (a)

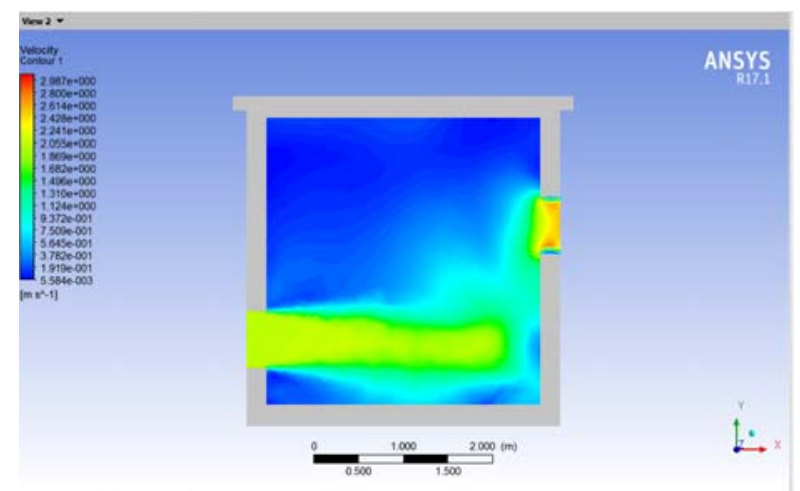

Fig. 3 (b)

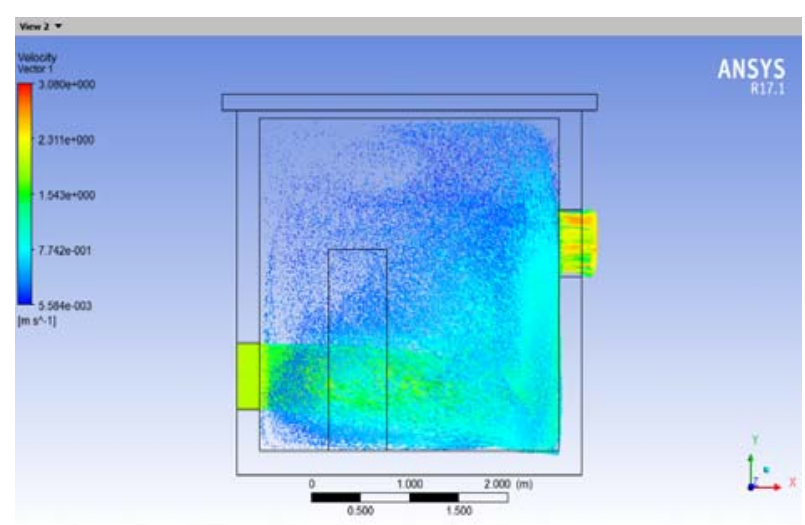

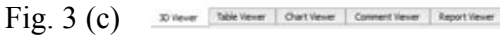

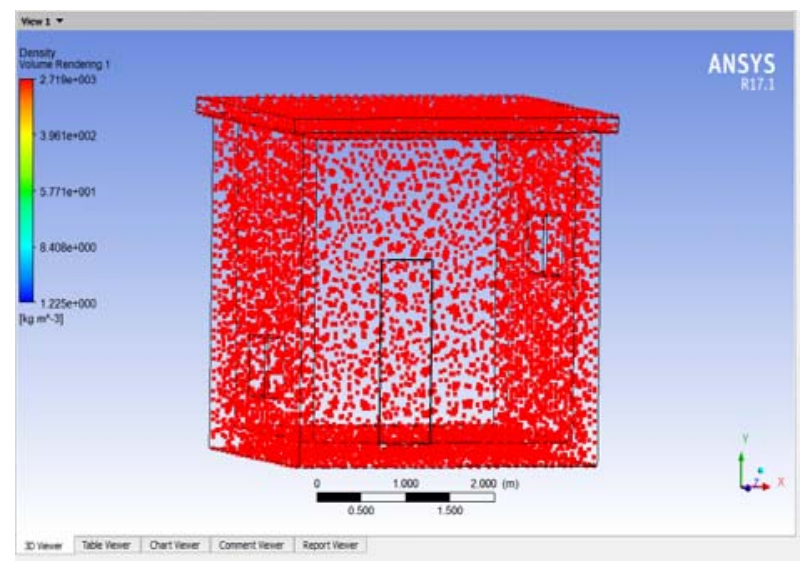

Fig. 3 (d)

Fig. 3. CFD results for room with square - shaped aperture (a) pressure (b) velocity (c) vector-velocity (d) density. 
V. Sivakumar et al. / JAFM, Vol. 10, Special Issue, pp. 61-68, 2017.

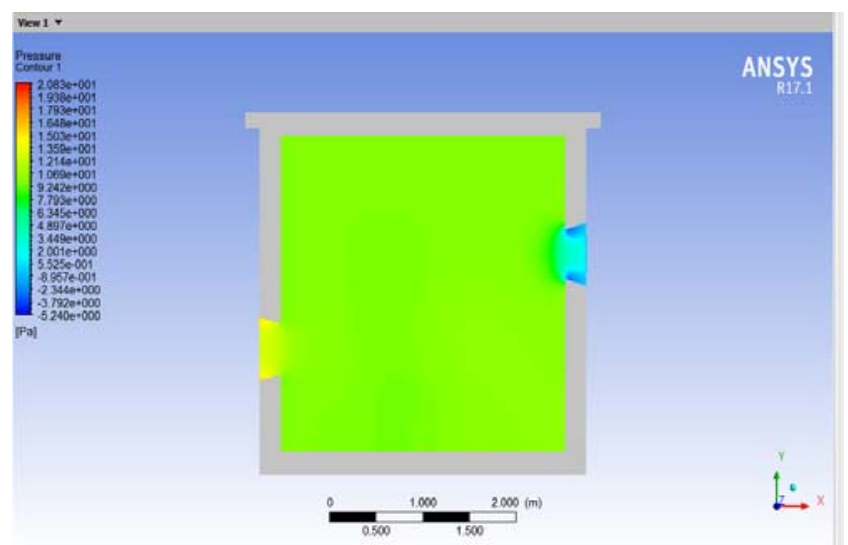

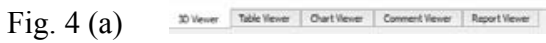

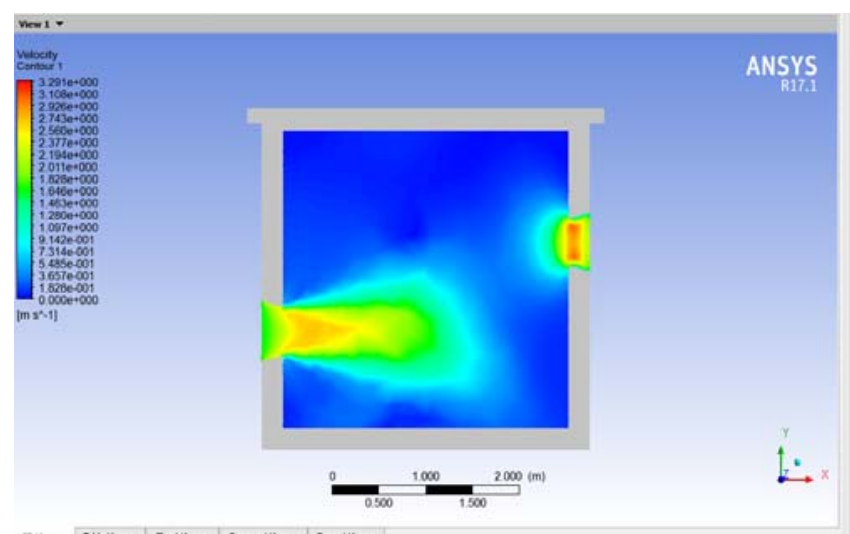

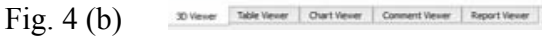

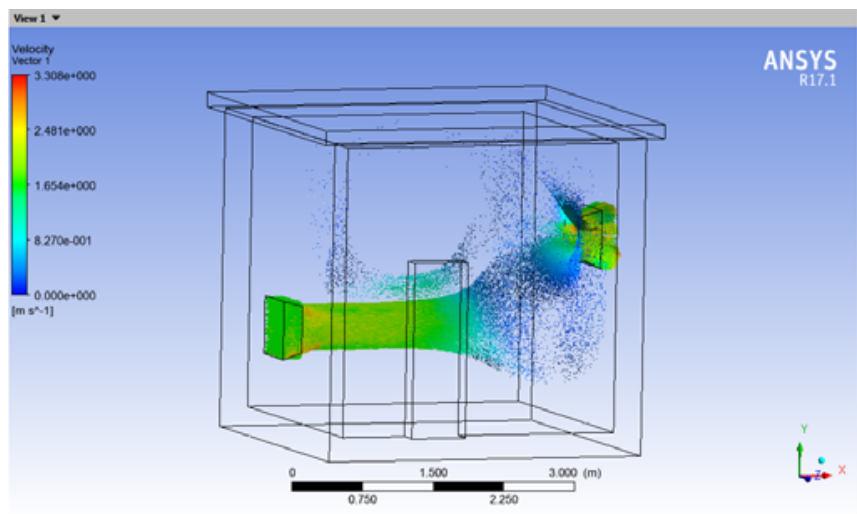

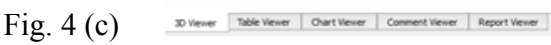

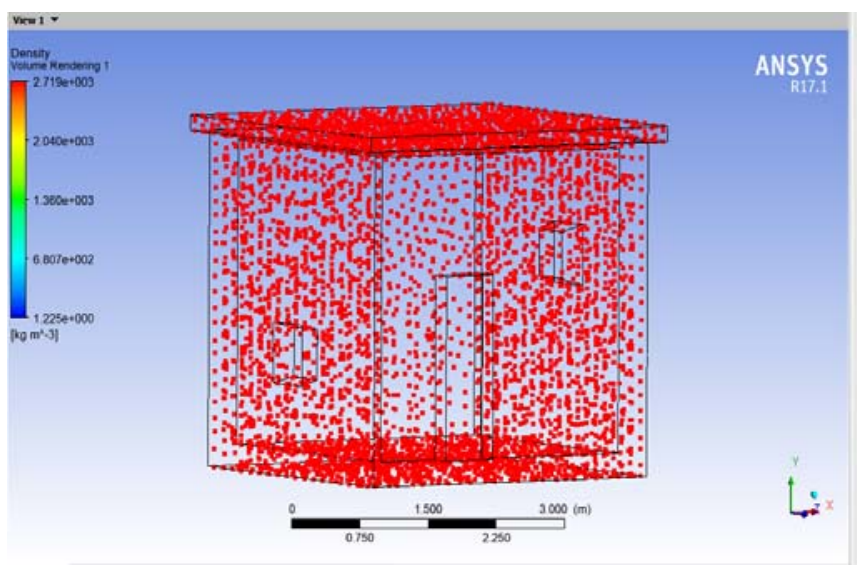

Fig. 4 (d)

Fig. 4. CFD results for room with convergent - divergent aperture (a) pressure (b) velocity (c) vectorvelocity (d) density. 
V. Sivakumar et al. / JAFM, Vol. 10, Special Issue, pp. 61-68, 2017.

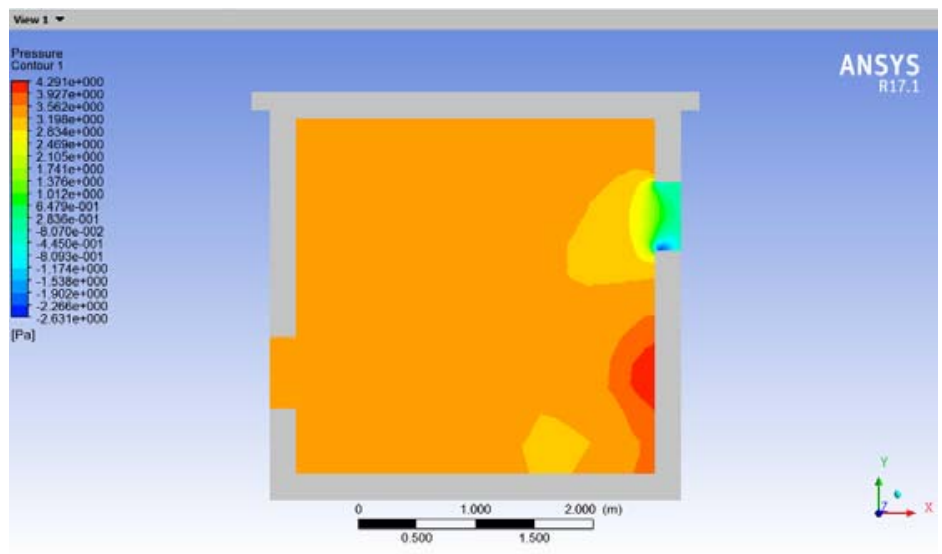

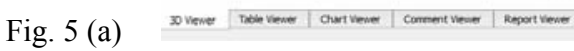

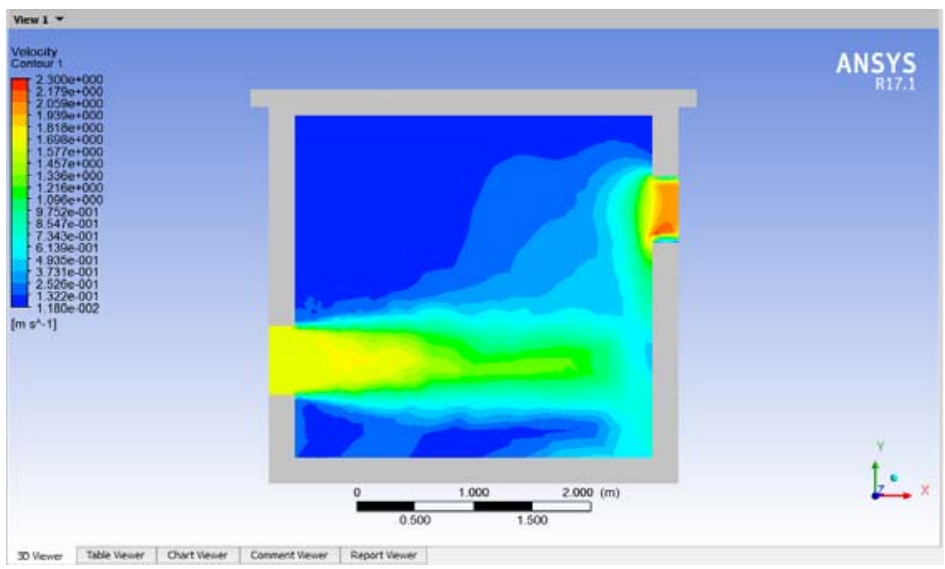

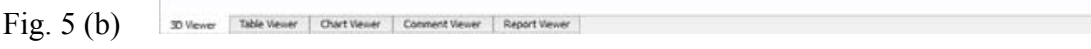

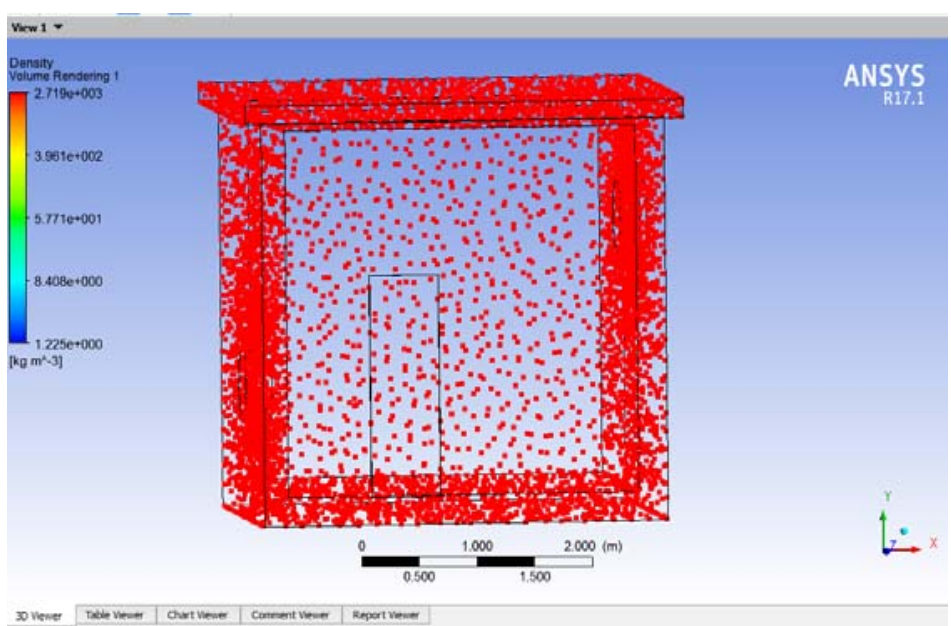

Fig. 5 (c)

Fig. 5. CFD results for room with circular aperture (a) pressure (b) velocity (c) density.

\section{CASE 2:}

Secondly, a convergent-divergent type of apertures is used. The inlet has a convergent shaped aperture and the outlet has a divergent shaped aperture as these structures could increase the velocity of the air passing through the room. Here in the inlet, the opening has an area of $2 \times 2 \mathrm{ft}$ and drafts about 25

and then converges. The outlet has the exact opposite dimensions on its both sides. The apertures are kept at heights $\mathrm{h} 1=4 \mathrm{ft}$ and $\mathrm{h} 2=6 \mathrm{ft}$ from the floor and the results are analyzed.

\section{CASE 3:}

Finally, a third cross-section was selected to have a circular shape. Here, the openings have a radius of 2 $\mathrm{ft}$ and were placed at different heights on the opposite walls. The openings are assumed at heights $\mathrm{h} 1=4 \mathrm{ft}$ and $\mathrm{h} 2=6 \mathrm{ft}$ from the floor and the results are observed. 


\section{RESULTS AND DISCUSSION}

From the theoretical calculations, we can find that to have an air change rate of $4.76 \mathrm{~h}^{\wedge}(-1)$ we must have an inlet velocity of $0.11 \mathrm{~m} / \mathrm{s}$. An analysis was made with this inlet velocity and the results were taken. The results obtained are shown below:

\section{CASE 1:}

Now, the results taken for the analysis of the square - shaped aperture using buoyancy effect are shown and are then compared with the other cases. The inlet velocity is given as $1.66 \mathrm{~m} / \mathrm{s}$ which was taken from weather data.

\section{CASE 2:}

The analysis made with the convergent inlet and divergent outlet is shown with their results. The analysis starts with an inlet velocity of $1.66 \mathrm{~m} / \mathrm{s}$ and the flows emerges out of the room through the outlet. The flow process can be found below:

\section{CASE 3:}

The analysis with inlet velocity $1.66 \mathrm{~m} / \mathrm{s}$ given through the circular opening is carried out and the final results are shown below. The results of all three cases are compared and the optimum design is found.

\section{CONCLUSION}

This study relates the air movements during natural ventilation through both analytical and finite volume methods. It can be observed that the solutions to the ventilation problems can be solved easily and effectively using numerical solutions. The pressure and velocity changes in the room for three different aperture shapes are noted. From the results, it can be found that the square - shaped apertures take in the maximum amount of air intake and the air flows along the entire room. Also, this type has the good balance between high velocity and the low pressure. Hence, among these three cases, square - shaped apertures would give better ventilation rate to the room. For future research, the size of the window of cross - sided ventilated room may be changed and analyzed for better air flow.

\section{REFERENCES}

Allocca, C., Q. Chen, and L. R. Glicksman (2003). Design analysis of single-sided natural ventilation, Energy and Buildings 35(8), 785795.

Chrysanthi (Sandy) Karagkouni, Ava Fatah gen Schieck, Martha Tsigkari, and Angelos Chronis (2103). Façade apertures optimization: Integrating cross-ventilation performance analysis in fluid dynamics simulation", Proceedings of the Symposium on Simulation for Architecture and Urban Design, Article 16.

Domkundwar, A. and A. V. Domkundwar (2015). A course in Refrigation and Air-conditioning, Dhanpat Rai Publications.

Stavrakakis, G. M., P. L. Zervas, H. Sarimveis and N. C. Markatos (2012). Optimization of window-openings design for thermal comfort in naturally ventilated buildings, Applied Mathematical Modelling 36(1), 193-211.

Jaina, J. M. and Brothers (2012). Uniform Mechanical Code-India.

Sinha, S. L., R. C. Arora and R. Subhransu (2002). Numerical prediction of the laminar two dimensional room air flows with and without buoyancy, Fluid Mechanics and Fluid Power 563-568.

The Engineering Toolbox, Rates of outdoor air supply [online] available at http://www.engineeringtoolbox.com/ventilatio n-air-flow-rate-d_115.html 